\title{
Heterogeneity and Developmental Alteration of Esterase Isoenzymes in Conidial Germination of Neurospora crassa
}

\author{
By TAKESHI EGASHIRA \\ Department of Biology, Kyushu Dental College, Kitakyushu 803, Japan
}

(Received 6 February 1986; revised 16 June 1986)

\begin{abstract}
At least 11 esterase isoenzymes have been resolved from conidia of six strains of Neurospora crassa on starch gel zymograms using $\alpha$-naphthyl acetate as substrate. By means of inhibitor studies, three of them were determined to be acetylesterases and nine to be carboxylesterases. Carboxylesterases could be distinguished from acetylesterases by their positive reaction with $\alpha-$ naphthyl butyrate. The distribution of these multiple forms of esterases in conidia was clearly strain specific. Each strain contained two forms of acetylesterase and from zero to three forms of carboxylesterase. These esterases could not hydrolyse the naphthyl esters of aliphatic carboxylic acids larger than butyrate or that of benzoate. During the first $20 \mathrm{~h}$ of conidial germination, a marked decrease in esterolytic activity was observed for most of the carboxylesterases but not for the acetylesterases. This might indicate that digestion of aliphatic esters is involved in the initial stage of conidial germination.
\end{abstract}

\section{INTRODUCTION}

Gel electrophoresis of esterase isoenzymes has been widely used for taxonomic, genetic and cell developmental studies in many organisms. So far, however, little information on the esterase isoenzymes of Neurospora has been published. Reddy \& Threlkeld (1971, 1972), using polyacrylamide gel electrophoresis, showed a single type of esterase activity in mycelial extracts from 18 strains of $N$. crassa. Sagarra (1973), on the other hand, reported esterase polymorphism in mycelia. The present author, using starch gel electrophoresis, demonstrated at least 7 sites of esterase activity in $N$. crassa conidia, and discussed a possible role of some of these isoenzymes in relation to conidial germination (Egashira, 1983).

The present study was designed to obtain information, using starch gel electrophoresis, about esterase heterogeneity in six strains of $N$. crassa. The alterations of esterase zymograms with development were investigated with the aim of determining the contribution of esterases to conidial germination.

\section{METHODS}

Growth. The six strains of Neurospora crassa listed in Table 1 were grown on synthetic minimal medium (Beadle \& Tatum, 1945) for 7-10 d at $27^{\circ} \mathrm{C}$. Conidia were harvested using glass wool and were washed repeatedly with distilled water. To obtain germinating conidia and mycelia, conidia were suspended in $30 \mathrm{ml}$ minimal medium in $100 \mathrm{ml}$ Erlenmeyer flasks and incubated at $27^{\circ} \mathrm{C}$ for $20 \mathrm{~h}$ on a reciprocal shaker.

Preparation of cell-free extracts. Washed cells were disrupted with a Teflon-glass homogenizer or an Edmund Buhler Vibriogen cell mill. Cell debris was removed by centrifugation for $30 \mathrm{~min}$ at $10000 \mathrm{~g}\left(4^{\circ} \mathrm{C}\right)$. The crude extracts were applied to the starch gel by inserting pieces of filter paper $(5 \times 6 \mathrm{~mm})$ previously wetted with the sample solution. Protein contents in the extracts were adjusted to approximately $6 \mathrm{mg} \mathrm{ml}^{-1}$.

Starch gel electrophoresis. Tris/EDTA/borate buffer (pH 8.7) was used, as described by Markert \& Faulhaber (1965). In the preparation of gel, 38.5-41 $\mathrm{g}$ starch, depending on the batch of hydrolysed starch, was suspended in $400 \mathrm{ml}$ buffer. Electrophoresis was usually for $5.25 \mathrm{~h}$ in a horizontal gel apparatus (Toyo HW) with a constant current of $34 \mathrm{~mA}(1.7 \mathrm{~mA}$ per $\mathrm{cm}$ gel width).

Abbreviations: DFP, diisopropyl fluorophosphate; PCMB, p-chloromercuribenzoic acid. 
Table 1. Strains of $N$. crassa

\begin{tabular}{rcl}
$\begin{array}{c}\text { FGSC } \\
\text { stock no. }\end{array}$ & $\begin{array}{c}\text { Mating } \\
\text { type }\end{array}$ & \multicolumn{1}{c}{ Strain designation } \\
821 & A & Formerly denoted as 4A \\
851 & A & Costa Rica \\
1131 & A & Panama CZ30.6 \\
2227 & A & Roanoke-1 \\
987 & A & 74-OR23-1A \\
2225 & A & Mauriceville-1C
\end{tabular}

Place and date of collection, and comments

Ascospore colour mutant carrying $t s$ gene

Coto 1958, wild-type

Canal Zone 1944, wild-type

Roanoke, Louisiana 1972, wild-type

Derived from Oak Ridge wild-type

Mauriceville, Texas 1972, wild-type

Staining. The esterases were stained within the gel using Fast Blue RR and various substrates. To examine the effect of diisopropyl fluorophosphate (DFP), $p$-chloromercuribenzoic acid (PCMB), eserine sulphate and heat treatment, $\alpha$-naphthyl acetate was used as substrate.

Treatments with esterase inhibitors. Esterase inhibitors were tested by preincubating the gels for $20 \mathrm{~min}$ in a solution of the inhibitor in $0.05 \mathrm{M}$-phosphate buffer $(\mathrm{pH} \mathrm{7.0)}$. The gels were then placed in the esterase reaction mixture to which the inhibitor had also been added.

Heat treatments. To determine the effect of heat on esterase activity, the cell-free extracts were heated at $40{ }^{\circ} \mathrm{C}$ for $20 \mathrm{~min}$ before electrophoresis.

Reagents. Hydrolysed starch was obtained from Connaught Laboratories, Fast Blue RR and the substrates from Sigma, DFP from Fluka, eserine sulphate from Merck, and PCMB and other chemicals from Wako Pure Chemical Industries.

\section{RESULTS AND DISCUSSION}

Gel density is critical for electrophoretic separation of isoenzymes. Starch gel electrophoresis provided satisfactory resolution of esterase isoenzymes in the crude cell-free extracts of $N$. crassa so long as the gels were rather flexible. Rigid starch gels or acrylamide gels $(7 \%)$ were less satisfactory.

The results obtained are shown in Figs $1-3$ and are summarized in Table 2.

\section{Polymorphism of esterase isoenzymes in $N$. crassa conidia}

With $\alpha$-naphthyl acetate as substrate, two to five bands were usually detected in each conidial extract. Taking the six strains together, a total of at least 11 bands was discerned (Fig. $1 a$ ): these bands are numbered from 1 to 11 in order from the anode to the origin. Although there was no significant difference in mobility between band 3 in strain 1131 and band 4 in strain 2225, different band numbers were given to these isoenzymes because of their different esterase properties as described later. The number of bands ranged from two (strain 2225) to five (strain 821 , sites $1,6,8,9$ and 11 ). Band 1 was detected in all the strains, and band 11 in all except strain 2225.

The enzyme banding pattern of strain 2227 was very similar to that of strain 987 , but there were minor differences in the electrophoretic mobilities of bands 5 and 7 in strain 2227 compared with bands 6 and 8 in strain 987. Strain 851 was characterized by high enzymic activity at site 10 . The zymogram of strain 987 was identical to that previously reported for strain 38 (Egashira, 1983) as well as to that of strain 2282, which carries mutant genes un-5, al-2 and arg-13. The band distribution in strain 3201 was similar to that in strain 821 (data not shown).

In addition to these isoenzymes, which were highly reproducible, the heavily staining area near the origin could sometimes be resolved into three or four unstable bands, and several weak bands were distinguishable in front of site 1.

This polymorphism of esterase isoenzymes in conidia is in agreement with the observations of Sagarra (1973), who used acrylamide gel electrophoresis of mycelial extracts of $N$. crassa. Strains 1131 and 851 were used in both Sagarra's and the present study: the two studies produced very similar esterase zymograms. 

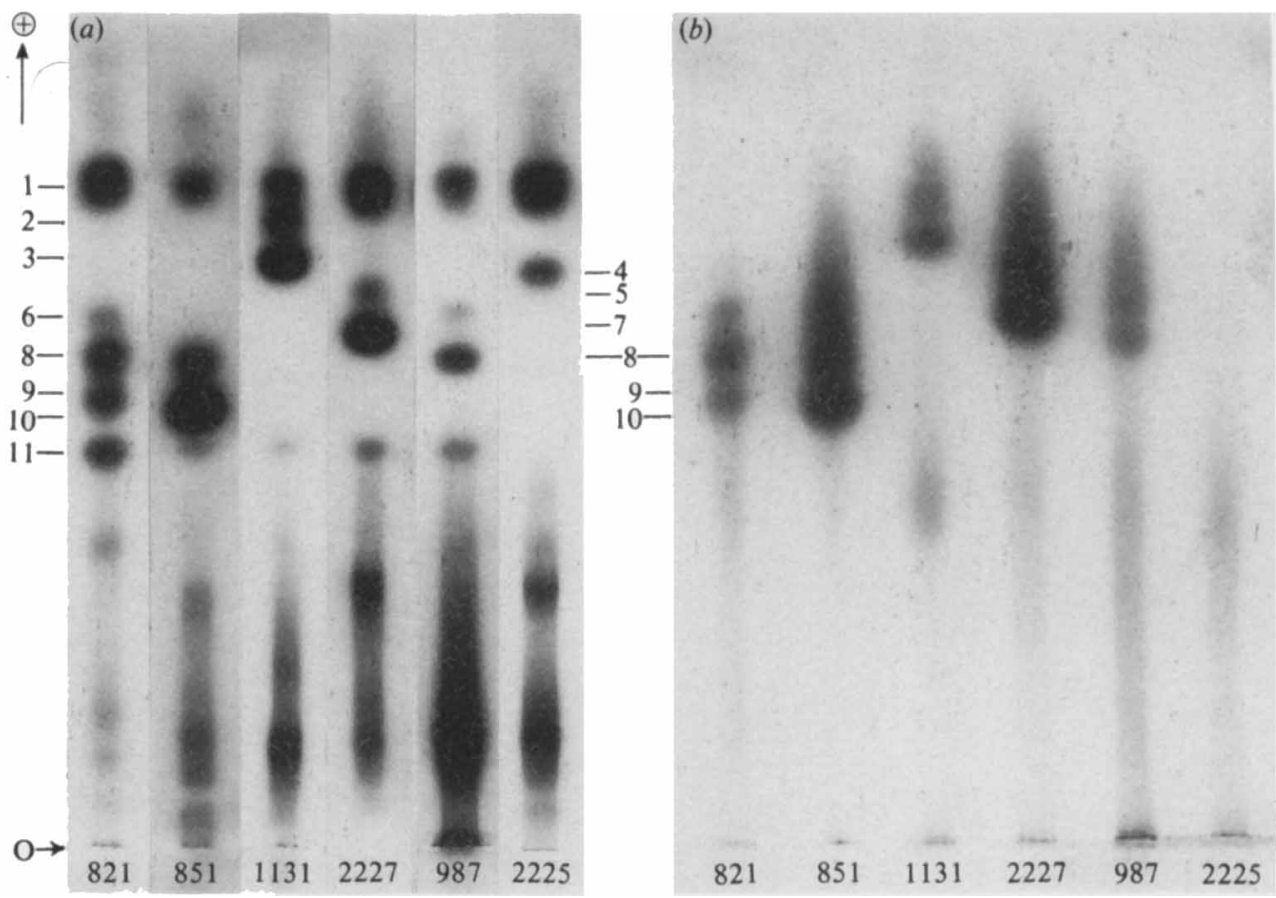

Fig. 1. Esterase zymograms for dormant conidia of six strains of $N$. crassa. The sites of active bands are numbered from 1 to 11 in order from the anode to the origin $(0) . \alpha$-Naphthyl acetate $(a)$ and $\alpha$-naphthyl butyrate $(b)$ were used as substrates in the staining reaction. Bands in the region from sites 2 to 10 , except site 4 in strain 2225 , can react with $\alpha$-naphthyl butyrate as well as with $\alpha$-naphthyl acetate.

\section{Substrate specificity}

The specificity of the esterase isoenzymes was tested with various substrates. When $\beta$ naphthyl acetate or indoxyl acetate was used as substrate, the esterase band patterns of the six strains were identical to those with $a$-naphthyl acetate, although $\beta$-naphthyl acetate was a relatively poor substrate. In contrast, when $\alpha$-naphthyl butyrate was used as substrate bands 1,4 and 11 were not clearly evident (Fig. $1 b$ ).

When naphthyl esters of aliphatic carboxylic acids larger than butyrate were used, there was a drastic decrease in esterolytic activity. None of the bands showed a positive reaction with any of the naphthyl esters of valerate, caproate, laurate or myristate, indicating that $N$. crassa does not contain lipase. There was also no evidence for the hydrolysis of the aromatic ester, $\beta$-naphthyl benzoate.

\section{Classification of $N$. crassa esterases}

Esterases can be classified on the basis of their reactions to physical and chemical inhibitors. Eserine sulphate inhibits cholinesterases, whereas DFP inhibits both cholinesterases and carboxylesterases. PCMB inhibits arylesterases, whereas acetylesterases are not inhibited by DFP, eserine sulphate or PCMB (Holmes \& Masters, 1967).

Esterase isoenzymes from dormant conidia were subjected to various treatments. The results from heat treatments at $40^{\circ} \mathrm{C}$ for $20 \mathrm{~min}$ and DFP $(0.1 \mathrm{mM})$ treatment are shown in Fig. 2 . Neither eserine sulphate $(0.01 \mathrm{mM})$ nor PCMB $(0.1 \mathrm{~mm})$ significantly affected esterolytic activity. The isoenzymes at sites 1,4 and 11 were resistant to both heat and DFP treatments (Fig. 2), and are therefore assumed to be acetylesterases. The other isoenzymes, which were 

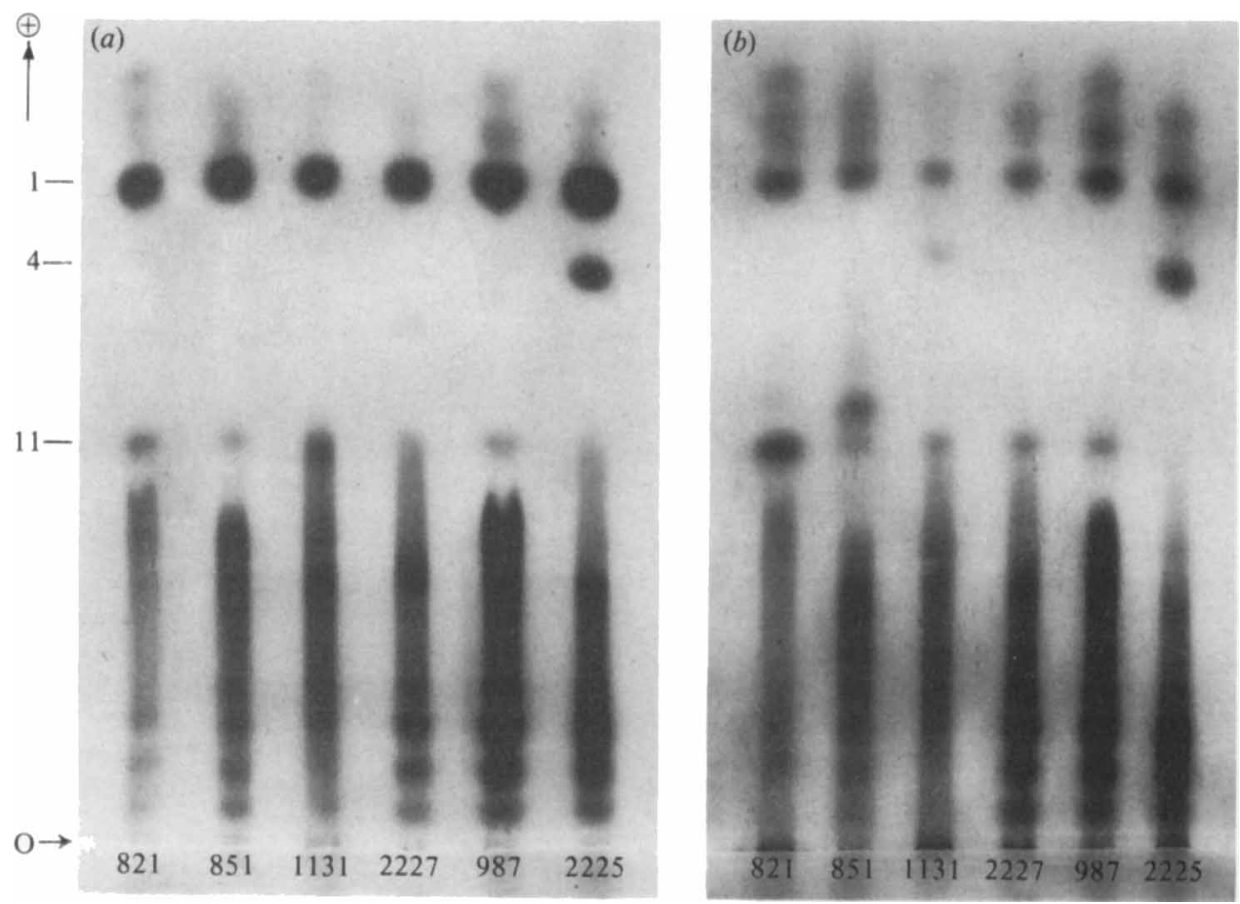

Fig. 2. Esterase zymograms for extracts of dormant conidia heated at $40{ }^{\circ} \mathrm{C}$ for $20 \mathrm{~min}(a)$ or treated with $0.1 \mathrm{mM}$-DFP $(b)$.
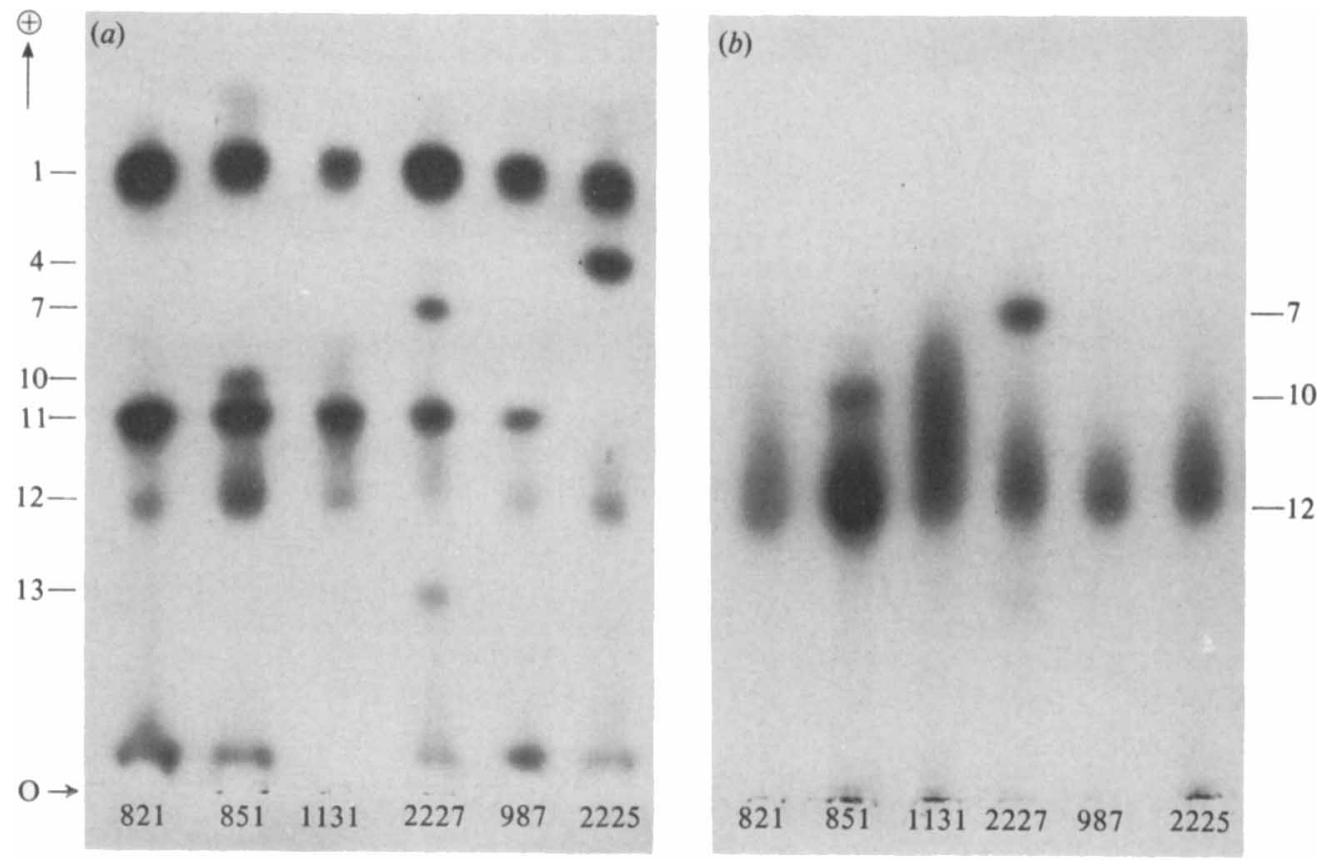

Fig. 3. Esterase zymograms for conidial germinants grown at $27^{\circ} \mathrm{C}$ for $20 \mathrm{~h}$, and reacted with $\alpha$ naphthyl acetate $(a)$ or $\alpha$-naphthyl butyrate $(b)$. Bands that were $\alpha$-naphthyl butyrate positive in dormant conidia show no or lowered activities in germinants. Note the increased relative activities of band 4 or 11 to band 1 in germinants. Band 12 became apparent in germinants and reacted strongly with $\alpha$-naphthyl butyrate. 
Table 2. Esterase isoenzymes of $N$. crassa

$\begin{array}{ccccc}\begin{array}{c}\text { Enzyme } \\ \text { band }\end{array} & \begin{array}{c}\text { Activity on } \\ \alpha \text {-naphthyl } \\ \text { butyrate }\end{array} & \begin{array}{c}\text { Activity } \\ \text { after } \\ \text { heating }\end{array} & \begin{array}{c}\text { Activity in } \\ \text { presence of } \\ \text { DFP }\end{array} & \begin{array}{c}\text { Presence in } \\ \text { germinated } \\ \text { conidia }\end{array} \\ 1 & - & + & + & + \\ 2 & + & - & - & - \\ 3 & + & - & - & - \\ 4 & - & + & + & + \\ 5 & + & - & - & - \\ 6 & + & - & - & - \\ 7 & + & - & - & - \\ 8 & + & - & - & - \\ 9 & + & - & - & - \\ 10 & + & - & - & - \\ 11 & - & + & + & +\end{array}$

sensitive to both treatments, must be carboxylesterases (Holmes \& Masters, 1967). Isoenzyme 4 was detected only in strains lacking isoenzyme 11, indicating that these two isoenzymes may be different molecular forms coded by the same structural gene. This presumption is supported by their identical reactions to substrates.

\section{Alteration in isoenzyme patterns during conidial germination}

When conidia were allowed to germinate in minimal medium at $27^{\circ} \mathrm{C}$ for $20 \mathrm{~h}$ and zymograms were prepared with $\alpha$-naphthyl acetate as substrate, certain isoenzymes which had been present in the dormant conidia were absent. The isoenzymes which decreased in activity in germinants were the carboxylesterases showing a positive reaction to $\alpha$-naphthyl butyrate in dormant conidia (compare Figs $3 a$ and $1 b$ ). Bands 1, 4 and 11, on the other hand, which were specific to $\alpha$-naphthyl acetate, remained and their activities increased in germinants as compared to conidia. From the above results, no detectable bands at sites 1-11 were expected in germinants when $\alpha$-naphthyl butyrate was used as substrate. Such was indeed the case, with the exception of some decreased activity at sites 7 and 10 (Fig. $3 b$ ).

Two new bands, at sites 12 and 13, were detected on zymograms of germinants (Fig. $3 a$ ). Band 12 reacted strongly with $\alpha$-naphthyl butyrate, although the staining was diffuse (Fig. $3 b$ ). These alterations of esterase activities during development suggest that conidia may contain specific ester compounds which are digested in the initial stage of germination.

The author is grateful to Dr C. S. Gowans (University of Missouri - Columbia) for reading the manuscript.

\section{REFERENCES}

Beadle, G. W. \& Tatum, E. L. (1945). Neurospora. II. Methods of producing and detecting mutations concerned with nutritional requirements. American Journal of Botany 32, 678-685.

Egashira, T. (1983). The relationship between conidial germination and esterase activities in Neurospora crassa. Journal of General Microbiology 129, 1857-1863.

Holmes, R. S. \& Masters, C. J. (1967). The developmental multiplicity and isoenzyme status of cavian esterases. Biochimica et biophysica acta 132, 379-399.

MARKERT, C. L. \& Faulhaber, I. (1965). Lactate dehydrogenase isozyme patterns of fish. Journal of Experimental Zoology 159, 319-332.

REDDY, M. M. \& THRELKELD, S. F. H. (1971). Genetic studies of isozymes in Neurospora. I. A study of eight species. Canadian Journal of Genetics and Cytology 13, 298- 305.

RedDY, M. M. \& Threlkeld, S. F. H. (1972). Genetic studies of isozymes in Neurospora. II. Esterase. Canadian Journal of Genetics and Cytology 14, 527531.

SaGarRa, E. (1973). Esterase polymorphism in Neurospora. Neurospora Newisletter 20, 29. 
the capacity of an antiserum raised against live organisms of strain BS4 (agar) to abolish the resistance of this strain to intracellular killing by human phagocytes. Also, antisera raised against the putative determinant directly nullified the resistance of strain BS4 (agar) (Veale et al., 1978; Parsons et al., 1981). It was a reasonable working hypothesis (see Veale et al., 1978; Parsons et al., 1981) that the determinant of gonococcal resistance to killing by phagocytes might be detected by these methods.

The $20 \mathrm{kDa}$ protein was detected by sodium dodecyl sulphate polyacrylamide gel electrophoresis (SDS-PAGE) of an outer membrane fraction of strain BS4 (agar) called fraction 1b. The latter was obtained by gel filtration on Sephadex G75 of outer membrane vesicles (OMV) dissolved in an alkaline buffer containing sodium cholate (Parsons et al., 1985a). SDSPAGE showed that fraction $1 \mathrm{~b}$ contained proteins of about $60 \mathrm{kDa}$ and some principal OMPs as well as the $20 \mathrm{kDa}$ protein. When the areas of the gel containing the proteins of about $60 \mathrm{kDa}$, the principal OMPs and the $20 \mathrm{kDa}$ protein, and the gel between the $20 \mathrm{kDa}$ protein and the solvent front, were extracted, only the $20 \mathrm{kDa}$ protein had the biological activity described above (Parsons et al., 1985a). Also, a fraction equivalent to $1 \mathrm{~b}$, separated from the closely related phagocyte susceptible strain BSSH, showed no evidence of the $20 \mathrm{kDa}$ protein on SDS-PAGE (Parsons et al., 1985a). In relation to final purification of the $20 \mathrm{kDa}$ protein, it was probable that in fraction $1 \mathrm{~b}$ before treatment with SDS, some of the $20 \mathrm{kDa}$ protein was complexed with the other proteins and LPS due to incomplete dissociation of the OMV by the sodium cholate (Parsons et al., 1985a).

This paper describes the purification of the $20 \mathrm{kDa}$ protein from fraction $1 \mathrm{~b}$ without treatment with SDS, and its chemical and biological properties.

\section{METHODS}

Neisseria gonorrhoeae. Strain BS4 (agar) is relatively resistant to killing by human phagocytes. It was selected from a laboratory strain, BS (Kellogg type 2, small colony forming, pilate) by four passages through plastic chambers implanted subcutaneously in guinea pigs and then cultured once on agar medium (Penn et al., 1976, 1977: Parsons et al., 1979). Strain BSSH is susceptible to killing by phagocytes. It constituted the majority of the population of strain BS from which it was selected in vitro by its 'single highlight' (SH) colony morphology (Penn $e t$ al., 1977). Both strains were grown, stored and counted as described previously (Veale et al., 1975; Penn et al., 1976, 1977).

Extraction of crude OMV with sodium cholate. OMV were prepared from strain BS4 (agar) $\left(100 \mathrm{ml} ; 10^{11}\right.$ gonococci $\left.\mathrm{ml}^{-1}\right)$ in $1 \mathrm{M}$-lithium chloride and extracted with glycine/ $\mathrm{NaOH}$ buffer $(0.1 \mathrm{M}, \mathrm{pH} 9.5)$ containing sodium cholate $(1 \%, \mathrm{w} / \mathrm{v})$ as described previously (Parsons et al., 1982, 1985a). If not fractionated immediately, extracts were stored at $-20^{\circ} \mathrm{C}$.

Preparation of fraction $1 \mathrm{~b}$ from cholate extracts. This was as described previously (Parsons et al., 1985a), but larger amounts $\left(8-10 \mathrm{ml}\right.$ rather than 3-4 ml) of the cholate extract (about $1 \mathrm{mg}$ protein $\mathrm{ml}^{-1}$ and derived from about $5 \times 10^{11}$ gonococci $\mathrm{ml}^{-1}$ ) were applied to the column of Sephadex G75 (Pharmacia; $1 \mathrm{~m} \times 25 \mathrm{~mm}$ ). Fractions $(2 \mathrm{ml})$ corresponding to fraction $\mathrm{lb}$ (Parsons et al., 1985a) were pooled and, in earlier work, concentrated by negative pressure dialysis. Later this was done by freeze drying, dissolving in water $(4 \mathrm{ml})$ and desalting on a Sephadex G25 column $(1 \mathrm{~m} \times 25 \mathrm{~mm})$ with water elution. The final volume of the pooled fractions was adjusted to that of the original extract.

The protein profiles on SDS-PAGE of OMV of strain BS4 (agar), their sodium cholate extract and fraction lb are shown in Fig. 2 of Parsons et al. (1985a) and they form the basis of much of the biochemical work in this paper.

Refractionation of fraction $\mathrm{lb}$ on Sephadex G75. Fraction $1 \mathrm{~b}\left(8-10 \mathrm{ml}\right.$, derived from $5 \times 10^{11}$ gonococci $\left.\mathrm{ml}^{-1}\right)$, whose protein profile on SDS-PAGE is shown in Fig. 2 (lanes 4 and 5) of Parsons et al. (1985a), was refractionated on a column of Sephadex G75 $(1 \mathrm{~m} \times 15 \mathrm{~mm})$ with glycine/ $\mathrm{NaOH}$ buffer $(0.1 \mathrm{M}, \mathrm{pH} 9.5)$ containing sodium cholate $(1 \%, w / v)$ as eluant as described for the preparation of fraction $1 \mathrm{~b}$ (Parsons et al., 1985a). Elution was followed by monitoring $A_{279}$. The region where materials of $20 \mathrm{kDa}$ would elute was indicated by preliminary experiments under the same conditions with the following marker proteins: ribonuclease, chymotrypsinogen $A$, ovalbumin and bovine serum albumin (BSA) $(13 \cdot 7,25 \cdot 0,43 \cdot 0,67 \cdot 0 \mathrm{kDa}$ respectively) (Fig. 1). Fractions of the gonococcal extract in the $20 \mathrm{kDa}$ region were pooled, and concentrated by freeze drying and desalting on Sephadex G25 as described above. The volume of the final material was adjusted with phosphate buffered saline (PBS, Penn et al., 1976) to $1 / 25$ of the volume of the original cholate extract. Several batches contained 1-1.5 mg protein $\mathrm{ml}^{-1}$, representing about $5 \%$ of the protein in the original cholate extract of OMV (see above).

Purified pili from strain BS4 (agar). These were two of the four preparations described by Parsons et al. (1981) and contained about 1.0 and $1.2 \mathrm{mg}$ protein $\mathrm{ml}^{-1}$ respectively. 